\title{
Severe hepatopathy and celiac disease (CD)
}

\author{
Firwana $M^{*}$, benelberhdadi I, Aomari A and Ajana FZ \\ Department of Diseases of the Digestive System, Medicine C, CHU IBN SINA-University Souissi Med V- Rabat Morocco
}

\section{Introduction}

Celiac disease $(\mathrm{CD})$ is an autoimmune enteropathy linked to gluten intolerance, a disease with a genetic predisposition. Hepatic injury is one of the most common extraintestinal manifestations. We report our experience on cases of severe cryptogenetic liver disease and celiac disease.

\section{Materials and methods}

This is a descriptive retrospective study in the department of diseases of the digestive system Medicine C of IBN SINA Rabat, including all cases of chronic liver disease associated with celiac disease. We excluded from this study the other causes of chronic liver disease.

\section{Results}

Of a total of 248 cases of celiac disease observed in our department, 78 cases $(31.5 \%)$ had chronic associated liver disease, including 05 cases of severe liver disease. There are 3 women and 2 men with a sex ratio $\mathrm{F}$ / $\mathrm{H}$ of 1.5 , the average age was 35 years [25-57]. The diagnosis of celiac disease was made before the appearance of chronic liver disease in 04 patients with an average delay of 9.5 years, whereas only one patient had a chronic liver disease diagnosed 05 years before the discovery of celiac disease. The reason for consultation was mainly malabsorption diarrhea (5 cases). The physical examination found a syndrome of portal hypertension in 3 cases and is normal in 2 cases. In the biology, there was anemia in 4 cases including one case of pan cytopenia, one hepatic cytolysis in 4 cases. The abdominal ultrasound showed a chronic hepatic appearance \pm sign of HTP in 4 cases and normal in one case. The etiological balance of cytolysis was negative (B, C, autoimm, overload). Upper digestive endoscopy showed a rarefaction of duodenal folds in 3 cases, with signs of HTP in all patients. The histopathological study of the biopsies showed intraepithelial lymphocytosis $>30 \%$ with villous atrophy in all patients. Anti transglutaminase antibodies were positive in 04 patients and negative in 01 cases. The liver biopsy puncture, showed severe fibrosis (F3) in 03 cases and cirrhosis (F4) in 2 cases. All our patients are on gluten-free diet, with symptomatic treatment of portal hypertension. The evolution was marked by a stabilization of chronic liver disease and its complications. One case presented ascitic decompensation for poor compliance with the gluten-free diet. No case of $\mathrm{CHC}$ has been noted in our series.

\section{Discussion}

$\mathrm{MC}$ is an autoimmune enteropathy linked to gluten intolerance. The mechanism of immunological involvement is now known and represents a general enopathology model [1]. The classic form of the combination of diarrhea, amping, abdominal pain with flatulence, malabsorption (steator-rhe) is too well known to be cured (20\% of cases). Lentent (silent) forms are essentially atypical or atypical forms that pose a diagnostic problem [2].
At least 20 to $30 \%$ of patients with $\mathrm{CD}$ have extra-intestinal manifestations [3]; hepatic lesions, described for the first time in 1977, are the most common [4]. There are two main types of liver injury in cryptogenetic and autoimmune disease, cryptogenic lesions are the most common and are usually asymptomatic. The pathophysiology of hepatic involvement in CD is poorly known [5].

The diagnostic of cirrhosis, in our study, was suggested in front of the signs clinics and biological following: the circulation venous collateral, the splenomegaly, the Oesophageal varices at upper digestive fibroscopy and the Abnormalities of the tests liver. The diagnostic etiological remained negative despite (serology viral, immunological assessment negative, not of signs indirect of overload hepatic). The CD was found in the presence of total villous atrophy and the positivity of anti-tranglutaminase antibodies. This CD could explain cirrhosis. Recently, cases of $\mathrm{CD}$ and non-cirrhotic hypertension have been reported in the literature. [6-9]. Indeed, liver damage is common during $\mathrm{CD}$. And it is mainly represented by non-specific abnormalities of liver biologic tests ( 15 to $61 \%$ ). These attacks have the distinction of being generally soluble after initiation of a gluten-free diet. In rare cases, it is associated with more specific hepatitis attacks such as primary biliary cirrhosis (3 to $7 \%$ ), primary sclerosing cholangitis ( $2-3 \%$ ), autoimmune hepatitis often type 1 ( 3 to $6 \%$ ), hepatic steatosis (if severe malabsorption), viral hepatitis C (1.2\%), hepatitis granulomatosis, primary hemochromatosis and thrombosis of hepatic vessels $[5,10]$ . In these diseases, unlike the preceding forms, there is generally no improvement in hepatic function subregulated without gluten [11].

Exceptionally liver injury in the cirrhosis stage is indicative of a celiac disease as the case of our patient. The physiopathological mechanism is unknown (role of malabsorption and chronic malnutrition, intestinal microbial proliferation, increase of intestinal permeability, chronic intestinal inflammatory).

\section{Conclusion}

Celiac disease can lead to severe chronic liver disease. $7.6 \%$ in our series. Gluten-free diet had a big impact on the stability of the disease (80\%).

\section{References}

1. Schuppan D, Junker Y, Barisani D (2009) Celiac disease: from pathogenesis to novel therapies. Gastroenterology 137: 1912-1933. [Crossref]

${ }^{*}$ Correspondence to: Firwana M, Department of Diseases of the Digestive System, Medicine C, CHU IBN SINA-University Souissi Med V- Rabat Morocco, Tel: 00212678615806; E-mail: Medfirwana7@gmail.com

Key words: Keywords: hepatopathy, celiac disease, Hepatic injury

Received: April 18, 2019; Accepted: April 26, 2019; Published: April 29, 2019 
2. Rousset H (2002) [Unusual initial manifestations of celiac disease in adults]. Rev Med Interne 23 Suppl 1: 27s-31s. [Crossref]

3. Schuppan D (2000) Current concepts of celiac disease pathogenesis. Gastroenterology 119: $234-242$

4. Mounajjed T, Oxentenko A, Shmidt E, Smyrk T (2011) The liver in celiac disease: clinical manifestations, histologic features, and response to gluten-free diet in 30 patients. Am J Clin Pathol 136: 128-137. [Crossref]

5. Volta U (2009) Pathogenesis and clinical significance of liver injury in celiac disease. Clin Rev Allergy Immunol 36: 62-70. [Crossref]

6. M'saddek F, Gaha K, Ben Hammouda R, Ben Abdelhafidh N, Bougrine F, et al. (2007) [Idiopathic portal hypertension associated with celiac disease: one case]. Gastroenterol Clin Biol 31: 869-871. [Crossref]
7. Kara B, Sandikci M (2007) Successful treatment of portal hypertension and hypoparathyroidism with a gluten-free diet. J Clin Gastroenterol 41: 724-725. [Crossref]

8. Sharma BC, Bhasin DK, Nada R (2006) Association of celiac diseasewith non-cirrhotic portal? brosis. J Gastroenterol Hepatol 21: 332-334.

9. Zamani F, Amiri A, Shakeri R, Zare A, Mohamadnejad M (2009) Celiac disease as a potential cause of idiopathic portal hypertension: a case report. J Med Case Rep 3: 68 [Crossref]

10. Rubio-Tapia A1, Murray JA (2007) The liver in celiac disease. Hepatology 46: 16501658. [Crossref]

11. Kaukinen K, Halme L, Collin P, Färkkilä M, Mäki M, et al. (2002) Celiac disease in patients with severe liver disease:gluten-free diet may reverse hepatic failure. Gastroenterology 122: 881-888.

Copyright: (C2019 Firwana M. This is an open-access article distributed under the terms of the Creative Commons Attribution License, which permits unrestricted use, distribution, and reproduction in any medium, provided the original author and source are credited. 